\title{
Mesenchymal stem cells and Interleukin-6 attenuate liver fibrosis in mice
}

\author{
Ghazanfar Ali Nasir ${ }^{\dagger}$, Sadia Mohsin ${ }^{\dagger}$, Mohsin Khan, Sulaiman Shams, Gibran Ali, Shaheen N Khan \\ and Sheikh Riazuddin
}

\begin{abstract}
Background: Mesenchymal stem cell (MSC) transplantation has emerged as a promising therapy for liver fibrosis. Issues concerning poor MSC survival and engraftment in the fibrotic liver still persist and warrant development of a strategy to increase MSC potency for liver repair. The present study was designed to examine a synergistic role for Interleukin-6 (IL-6) and MSCs therapy in the recovery of carbon tetrachloride $\left(\mathrm{CCl}_{4}\right)$ induced injured hepatocytes in vitro and in vivo.
\end{abstract}

Methods: Injury was induced through $3 \mathrm{mM}$ and $5 \mathrm{mM} \mathrm{CCl}_{4}$ treatment of cultured hepatocytes while fibrotic mouse model was established by injecting $0.5 \mathrm{ml} / \mathrm{kg} \mathrm{CCl}_{4}$ followed by treatment with IL-6 and MSCs. Effect of MSCs and IL-6 treatment on injured hepatocytes was determined by lactate dehydrogenase release, RT-PCR for (Bax, BCl-Xl, Caspase3, Cytokeratin 8, NFKB, TNF-a) and annexin V apoptotic detection. Analysis of MSC and IL-6 treatment on liver fibrosis was measured by histopathology, PAS, TUNEL and Sirius red staining, RT-PCR, and liver function tests for Bilirubin and Alkaline Phosphatase (ALP).

Results: A significant reduction in $\mathrm{LDH}$ release and apoptosis was observed in hepatocytes treated with a combination of MSCs and IL-6 concomitant with upregulation of anti-apoptotic gene BCl-xl expression and down regulation of bax, caspase3, NFKB and TNF-a. Adoptive transfer of MSCs in fibrotic liver pretreated with IL-6 resulted increased MSCs homing and reduced fibrosis and apoptosis. Hepatic functional assessment demonstrated reduced serum levels of Bilirubin and ALP.

Conclusion: Pretreatment of fibrotic liver with IL-6 improves hepatic microenvironment and primes it for MSC transplantation leading to enhanced reduction of liver injury after fibrosis. Synergistic effect of IL-6 and MSCs seems a favored therapeutic option in attenuation of liver apoptosis and fibrosis accompanied by improved liver function.

Keywords: Mesenchymal stem cells, Liver fibrosis, Hepatocytes, Interleukin-6

\section{Background}

Mesenchymal stem cells (MSCs) are multipotent adult stem cells present in bone marrow, adipose tissue and cord blood and have emerged recently as an attractive candidate for liver repair. MSCs have been shown to form functional hepatocytes in vitro $[1,2]$ and possess the ability to secrete soluble factors stimulating endogenous parenchymal cells to support tissue recovery [3,4]. Moreover, MSC transplantation in a liver fibrosis model can reduce fibrosis [5] and restore depleted hepatic function [5-7].

\footnotetext{
* Correspondence: riazuddin@aimrc.org

${ }^{\dagger}$ Equal contributors

National Center of Excellence in Molecular Biology, University of the Punjab, 87-West Canal Bank Road, Lahore, Pakistan
}

Similarly, treatment with bone marrow derived stem cells can attenuate liver fibrosis by preservation of metalloproteinase levels in fibrotic liver [8].

During the course of liver fibrosis different cytokines, chemokines and growth factors are released as part of the inflammatory response. Among these secreted factors, IL-6 is a pleiotropic cytokine involved in inflammatory pathways, hematopoiesis and immune regulation. Recent evidence implicates IL-6 in survival and regeneration of hepatocytes through Nuclear Factor-kappa B $(N F-\kappa B)$ signal transduction and the Ras-MAPK (mitogen-activated protein kinase) pathway [9]. Increased liver injury was observed on $\mathrm{CCl}_{4}$ induction in IL-6-/- mice due to TNF- $\alpha$ production showing the role of IL- 6 downstream of TNF- $\alpha$

\section{Biomed Central}


in hepatoprotection [10]. Hepatocyte apoptosis is attenuated through IL-6 and many of the antiapoptotic genes like $B c l-x l, B c l-2$ and FLIP are upregulated [11]. Exogenous IL- 6 treatment corrected the defects in cell proliferation in IL-6-/- mice showing its role as mitogenic agent in liver regeneration after partial hepatectomy [12,13]. In addition, positive effects of IL-6 on proliferation and DNA synthesis have been observed on primary hepatocyte cultures [14].

Accumulating evidence suggests that MSCs can home and migrate to injured liver but are unable to differentiate into hepatocytes rather promoting fibrogenesis in vivo $[15,16]$. Moreover, issues with MSC engraftment and long term survival within hostile liver microenvironment may also adversely affect the outcome of MSC therapy for liver repair. The aim of the present study was to enhance MSC potential for hepatic repair after $\mathrm{CCl}_{4}$ induced liver injury in mouse. We hypothesized that priming hepatic microenvironment with IL-6 would allow an increase in MSC mediated regenerative response by imparting protection to existing hepatocytes. We demonstrate that IL-6 and MSCs synergistically enhance hepatic repair, reduce liver fibrosis and improve overall hepatic function compared to either of the treatments alone.

\section{Materials and methods}

\section{Animals}

The investigation conforms to the Guide for the Care and Use of Laboratory Animals published by the US National Institutes of Health (NIH Publication No. 85-23, revised 1985). All animals were treated according to procedures approved by the Institutional Review Board (IRB) at the National Center of Excellence in Molecular Biology, Lahore, Pakistan.

\section{Cell culture}

Mesenchymal stem cells (MSCs) were isolated from tibias and femora of 2 months old C57BL/6 mice $(n=10)$ according to their ability to adhere to plastic surface of a culture flask and were cultured as described previously [17].

\section{Hepatocyte isolation}

Hepatocytes were isolated from C57BL/6 mice $(n=20)$ according to the two step perfusion method as described previously [18]. Isolated hepatocytes were plated at a concentration of $1 \times 10^{4}$ cells $/ \mathrm{cm}^{2}$ in collagen coated plates (Becton Dickinson, USA) in RPMI 1640 medium (Sigma Aldrich, USA) supplemented with $100 \mathrm{ug} / \mathrm{ml}$ streptomycin (MP Biomedicals, USA), 100 units/ml penicillin (MP Biomedicals, USA) and 10\% fetal bovine serum (Sigma Aldrich, USA) in a humidified incubator at $5 \% \mathrm{CO}_{2}$ and $37^{\circ} \mathrm{C}$ temperature. Medium was replaced after 3 and 24 hrs after seeding followed by various treatments.

\section{In vitro co-culture model}

Hepatocytes were plated on a 6-well collagen coated plate (Becton Dickinson, USA) at a concentration of $1 \times 10^{4}$ cells $/ \mathrm{cm}^{2}$ and were subjected to injury with $3 \mathrm{mM}$ and $5 \mathrm{mM}$ Carbon tetrachloride $\left(\mathrm{CCl}_{4}\right.$, Merck, Germany) dissolved in DMSO (Merck, Germany) $[19,20]$. Injured hepatocytes were treated with Interleukin-6 [(IL-6, $10 \mathrm{ng} / \mathrm{ml})$ (Sigma Aldrich, USA)] for 24 hours followed by MSCs administration in a transwell culture system with Dulbecco's Modified Eagle Medium (DMEM) (sigma) medium having 10\% FBS, $100 \mathrm{U} / \mathrm{ml}$ penicillin and $100 \mu \mathrm{g} / \mathrm{ml}$ streptomycin. Hepatocyctes were divided into 5 groups as, non-treated, $\mathrm{CCl}_{4}$, IL-6, MSCs and MSCs + IL-6 treated hepatocytes. Co-culture lasted for 24 hours and hepatocytes were harvested for RNA extraction, apoptosis analysis and LDH cytotoxicity tests [21].

\section{LDH Assay}

Cytotoxicity was analyzed through Lactate dehydrogenase assay according to manufacturer's protocol (Sigma Aldrich, USA) in hepatocytes co-cultured with MSCs in the presence or absence of IL-6. Normal, $\mathrm{CCl}_{4}$ and IL-6 treated hepatocytes were used as controls. Assay was run in triplicate for each sample and absorbance was measured at $490 \mathrm{~nm}$ [22].

\section{Apoptosis}

FITC-Annexin V kit (Abcam, USA) was used for detection of apoptosis in all of the above mentioned in vitro groups 24 hours after co-culture. Cells were incubated with Annexin-V for 15 minutes, fixed in 2\% paraformaldehyde and stained with DAPI (MP Biomedicals, USA).

Apoptosis was estimated on frozen liver sections of control and treatment groups by TUNEL assay kit (Millipore, USA). Sections were fixed by $4 \%$ Paraformaldehyde and stained with TUNEL assay kit according to manufacturer's protocol. Three sections were selected for each mouse and three mice per treatment.

\section{$\mathrm{CCl}_{4}$ induced fibrotic liver model}

Female C57BL/6 mice (6-8 weeks old) were subjected to liver fibrosis by injecting $1 \mathrm{ml} / \mathrm{kg} \mathrm{CCl}$ (Merck, Germany) in olive oil (1:1) intraperitoneally for four weeks as previously described [23].

\section{In vivo IL-6 treatment}

IL-6 (Sigma Aldrich, USA) was administered at a dose of $100 \mu \mathrm{g} / \mathrm{kg}$ intraperitonealy 24 and 48 hours after completion of 4 week $\mathrm{CCl}_{4}$ treatment. Mice were divided into five groups i.e. non-treated, $\mathrm{CCl}_{4}$, IL-6, MSCs and MSCs + IL-6 treated mice with $n=10$ animals in each group. 


\section{MSC Transplantation}

MSCs were labeled with PKH-26 fluorescent cell linker dye (Sigma Aldrich, USA) for their detection in the liver post transplantation as shown previously [23]. MSCs + IL-6 groups received MSC transplantation 4 hours after completion of IL-6 injections. Anesthesia was induced and abdomen was neatly cut below diaphragm. After exposing liver, approximately $10^{6}$ cells $/ \mathrm{ml}$ were transplanted directly in to liver lobes at three lateral and two median sites with a $30 \mathrm{G}$ syringe.

\section{Periodic acid schiff (PAS) stain}

Periodic acid schiff [(PAS) (Sigma Aldrich, USA)] staining was performed for the estimation of glycogen storage levels in sections from all animal groups 30 days after MSCs and IL-6 treatment. After hydrating, paraffin sections were incubated in periodic acid for 5 minutes followed by staining with Schiffs reagent for 15 minutes and finally hematoxylin staining. Sections from three animals for each group and three sections per treatment were analyzed.

\section{Sirius red}

Sirius red staining provided assessment of the collagen deposition in $\mathrm{CCl}_{4}$ injured and treated liver sections 30 days after MSCs and IL-6 treatment. Nuclei were stained with hemotoxylin (Sigma Aldrich, USA) and then picro-sirius red stain (Direct red 80, Sigma) was applied for 1 hour.

\section{Gene expression}

Total RNA was extracted from injured and treated cells and also from liver tissues samples using TRIZOL (Invitrogen, USA). cDNA synthesis was carried out from $1 \mu \mathrm{g}$ of RNA sample using M-MLV reverse transcriptase (Invitrogen, USA). For analysis of gene expression in MSCs after various treatments, real time RT-PCR was carried out using SYBR Green PCR Super Mix (BioRad, USA), $8 \mathrm{mM}$ of each primer and $100-500 \mathrm{ng} / \mathrm{ml}$ of template cDNA on BioRad System iQ5. The relative ratio and standard deviation between the normal and treated samples were calculated using the comparative $\mathrm{Ct}$ method (DD Ct value), as recommended by the BioRad iQ5system. The expression of Bax, Bcl-xl, albumin, caspase-3, cytokeratin-8, NFKB, $T N F-\alpha$ was estimated by using Image J software. Bactin was used as internal control. All primer sequences have been mentioned in Table 1.

\section{Biochemical tests}

Blood samples were taken from all experimental groups 30 days after treatment with MSCs and IL-6. Serum was isolated and the amount of bilirubin (Diazyme Europe, Gmbh) and alkaline phosphatase (Bioassay System, USA) was estimated using commercial kits according to the manufacturer's protocol.
Table 1 Primer sequences

\begin{tabular}{ccc}
\hline Gene & Sequence & Product size \\
\hline Bax (F) & TGGAGATGAACTGGACAGCA & 182 \\
Bax (R) & CAAAGTAGAAGAGGGCAACCAC & \\
Bcl-xl (F) & TTCGGGATGGAGTAAACTGG & 150 \\
Bcl-xl (R) & AAGGCTCTAGGTGGTCATTCAG & \\
Albumin (F) & GCTGTAGTGGATCCCTGGTG & 196 \\
Albumin (R) & GCTGTAGCCTTGGGCTTG & \\
Cytokeratin-8 (F) & CTCACTAGCCCTGGCTTCAG & 232 \\
Cytokeratin-8 (R) & ACAGCTGTCTCCCCGTGA & \\
Caspase3 (F) & TGTCATCTCGCTCTGGTACG & 220 \\
Caspase 3 (R) & AAATGACCCCTTCATCACCA & \\
NF-kB (F) & GCACCTGTCCAAAGAGCAC & 200 \\
NF-kB (R) & GTGGAGTGAGACATGGACACAC & \\
TNF-a (F) & ACGGCATGGATCTCAAAGAC & 162 \\
TNF-a (R) & GGAGGTTGACTTCTCCTGGTA & \\
Bactin (F) & GCTGTGTTGTCCCTGTATGC & 106 \\
Bactin (R) & GAGCGCGTAACCCTCATAGA & \\
\hline
\end{tabular}

\section{Statistical analysis}

Quantitative data was obtained from 3 slides from each animal in different experimental groups for Sirius red staining and were expressed as means \pm SEM. Analysis for percentage of fibrosis between groups was performed by one-way ANOVA ( $p$ value of less than 0.05 was considered statistically significant) with bonferroni post-hoc test. Data from10 animals/group was analyzed for bilirubin and ALP.

\section{Results}

\section{In vitro hepatocyte injury model}

Hepatocytes were exposed to different concentrations of $\mathrm{CCl}_{4}$ i.e. $3 \mathrm{mM}$ and $5 \mathrm{mM}$ in medium for 2,4 and 6 hours. Expression of apoptotic markers such as Bax, and caspase- 3 was significantly upregulated in 6 hours group while $B c l-x l$ was downregulated as measured by RTPCR. Similarly, hepatic markers albumin and cytokeratin-8 were decreased with increase in $\mathrm{CCl}_{4}$ concentration and duration of treatment (Figure 1A). Concurrently, level of cytotoxicity as measured by LDH assay was significantly higher 6 hours after $5 \mathrm{mM} \mathrm{CCl}_{4}$ treatment (Figure 1B). Therefore, $5 \mathrm{mM} \mathrm{CCl}_{4}$ concentration for 6 hours was used in subsequent experiments with in vitro cultured hepatocytes.

\section{Enhanced hepatocyte protection in vitro after MSCs + IL-6 treatment}

Hepatocytes were subjected to $\mathrm{CCl}_{4}$ treatment $(5 \mathrm{mM}$ for 6 hours) followed by treatment with IL- 6 for 24 hours. At the end of IL- 6 treatment, MSCs were co-cultured with hepatocytes in a transwell system with or without IL-6. 

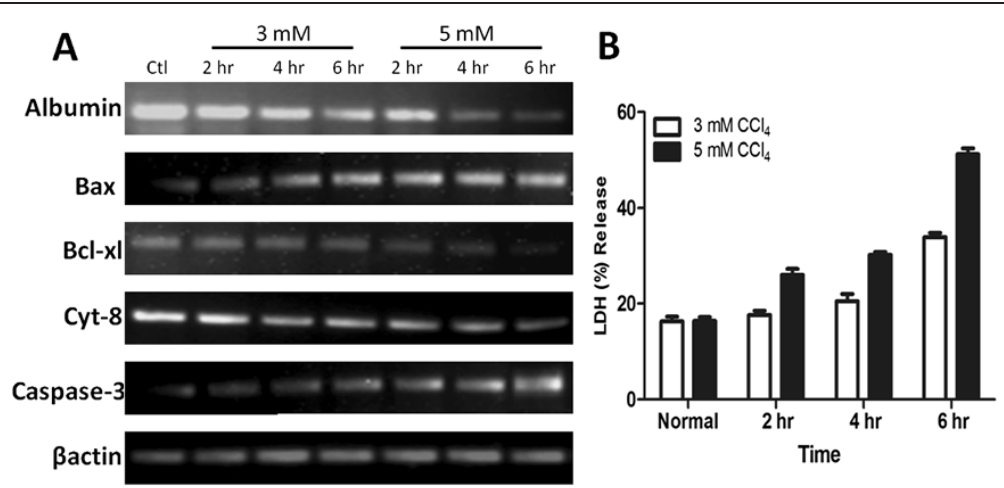

Figure 1 In vitro hepatocyte injury model. A) Gene expression analysis of hepatic (Albumin, Cytokeratin-8), apoptotic (Bax, caspase-3) and anti-apoptotic $(B C-x l)$ markers after $3 \mathrm{mM}$ and $5 \mathrm{mM} \mathrm{CCl}_{4}$ treatment is dose and time dependent as measured by RT-PCR $(n=3)$. B) LDH (\%) release in hepatocytes shows maximum release after $5 \mathrm{mM} \mathrm{CCl}_{4}$ treatment for 6 hours $(n=3)$.

Hepatocyte co-cultures were divided into five groups i.e. Non-treated, $\mathrm{CCl}_{4}$, IL-6, MSCs and MSCs + IL-6 treated hepatocytes. Analysis of gene expression showed reduction in apoptotic markers such as Bax, Caspase-3, NFkB and TNF- $\alpha$ in hepatocytes treated with MSCs and IL-6 alone compared to $\mathrm{CCl}_{4}$ group but a significant reduction was observed after treatment with MSCs + IL-6 compared to all other groups. Similarly, increased levels of anti apoptotic marker Bcl-xl was observed after MSCs and IL-6 treatment alone but a greater reduction was observed after combined treatment of MSCs + IL-6 compared to $\mathrm{CCl}_{4}$ treated hepatocytes (Figure 2A-B). Significant reduction in LDH levels was observed in IL-6 (32.5 $\pm 1.8 \%)$ and MSCs $(31.2 \pm 1.5 \%)$ treated injured hepatocytes (Figure 2C). However, treatment with MSCs + IL-6 showed significant higher reduction $(21.6 \pm 1.6 \%)$ in cell injury than any other treatment groups. Conversely, level of apoptosis as measured by Annexin-V staining was lower in IL-6 $(20.7 \pm 1.4 \%)$ and MSCs $(17.9 \pm 0.9 \%)$ compared to $\mathrm{CCl}_{4}(27.0 \pm 2.0 \%)$. However, MSCs $+\mathrm{IL}-6$ treatment

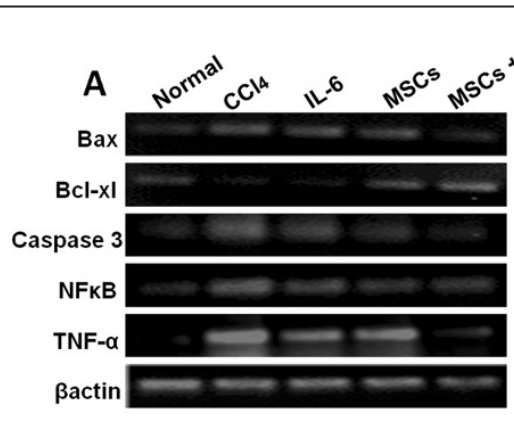

C

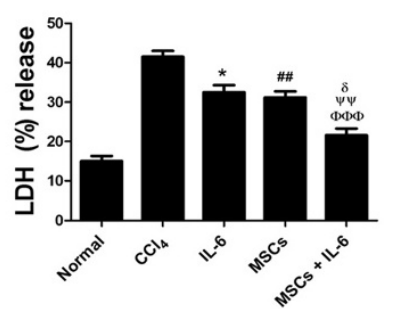

B

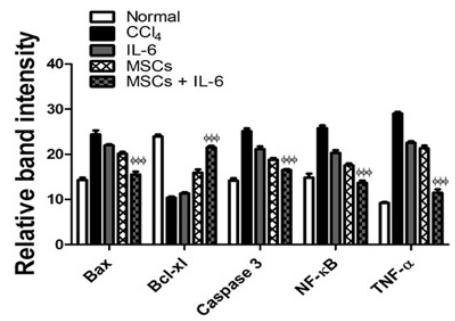

D

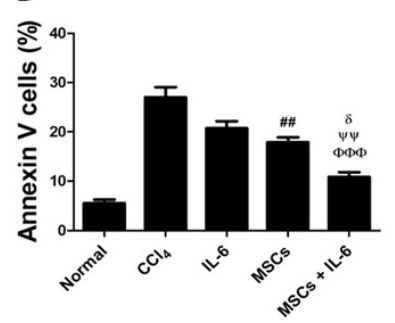

Figure 2 Enhanced hepatocyte survival after co-culture with MSCs + IL-6. A) Gene expression of apoptotic (Bax, caspase-3, NF-kB, TNF- $\alpha$ ) and anti-apoptotic $(B C l-x)$ markers in hepatocytes co-cultured with MSCs together with IL-6. B) Gel band quantification of gene expressions through

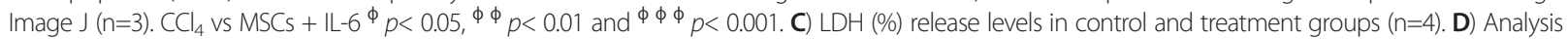

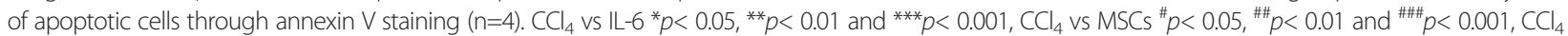

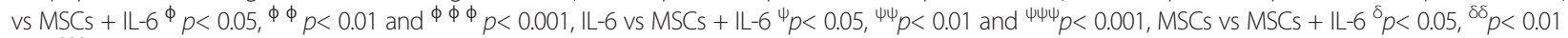
and ${ }^{\delta \delta \delta} p<0.001$. 
$(10.8 \pm 0.9 \%)$ showed significant reduction in Annexin-V staining compared to all other groups (Figure 2D).

\section{Homing of transplanted MSCs}

MSCs labeled with PKH 26 and DAPI were transplanted into fibrotic livers in the presence or absence of IL-6. Increased homing in fibrotic liver from MSCs + IL-6 (Figure 3A-C) treatment group was observed as evidenced by increased number of PKH-26/DAPI colabeled cells $(31 \pm 3.2$ cells $\left./ \mathrm{mm}^{2}\right)$ compared to MSCs $\left(20 \pm 1.2\right.$ cells $\left./ \mathrm{mm}^{2}\right)$ only transplantation group thus showing augmentation of MSC homing and engraftment in fibrotic livers treated with IL-6.

\section{Reduced fibrosis and apoptosis in $\mathrm{CCl}_{4}$ injured liver after} treatment with MSCs + IL-6

In order to demonstrate the combined treatment effect of MSCs and IL-6 on fibrosis and apoptosis in fibrotic liver, liver section from all treatment groups were stained with Sirius red for fibrosis and TUNEL staining for apoptosis detection. Mice treated with IL-6 and MSCs alone showed reduction in fibrosis which was $3.1 \pm 0.4 \%$ and $2.1 \pm 0.3 \%$ respectively compared to $\mathrm{CCl}_{4}$ treated animals $(4.5 \pm 0.1 \%)$ as evidenced by sirius red staining (Figure 4A-F). However, significant reduction in fibrosis was observed in MSCs + IL-6 treatment group (0.9 \pm $0.2 \%)$ compared to all other groups. Conversely, TUNEL+ cells were reduced in fibrotic liver after IL-6 (28 $\pm 0.9 \%)$ and MSCs $(20 \pm 1.6 \%)$ compared to $\mathrm{CCl}_{4}(39 \pm 0.5 \%)$ treatments (Figure 4G-L). However, there was significant reduction in TUNEL+ cells in MSCs + IL-6 (9 $\pm 1.5 \%)$ group compared to all other groups.

\section{Improved hepatocyte survival and function in vivo after MSCs + IL-6 treatment}

PAS staining of liver sections from all animal groups was done to evaluate the effect of combined treatment of MSCs and IL-6 on restoration of functional hepatocytes in liver damaged by $\mathrm{CCl}_{4}$ treatment. It was demonstrated that animals treated with MSCs + IL-6 showed high levels of glycogen storage compared to MSCs, IL-6 and $\mathrm{CCl}_{4}$ treated groups as evidence by PAS staining (Figure 5A-D). In addition, increased expression of $B c l-x l$ was observed in livers treated with MSCs + IL-6 compared to groups treated with either MSCs or IL-6 and $\mathrm{CCl}_{4}$ (Figure 5F). Similarly, expression levels of apoptotic markers such as Bax, caspase-3, NF- $K B$ and TNF- $\alpha$ demonstrated significant reduction after combined MSCs + IL-6 administration compared both treatment alone and $\mathrm{CCl}_{4}$ treated groups (Figure 5E) providing evidence that MSCs + IL-6 administration enhances glycogen storing ability of hepatocytes, promotes survival and decreases apoptotic signaling.

\section{Biochemical functions}

To further evaluate the role of combined treatment with MSCs and IL-6 on augmentation of liver function, serum levels of Alkaline phosphatase (ALP) and Bilirubin were analyzed in all treatment groups. Serum levels of ALP were significantly lower in mice receiving combined treatment with MSCs + IL-6 (208 units/L) compared to treatment with IL-6 (450 units/L), MSCs (390 units/L) and $\mathrm{CCl}_{4}$ (613 units/L) groups (Figure 6A). Similarly, Bilirubin level in MSCs + IL-6 treated group was $0.4 \mathrm{mg} / \mathrm{dl}$, which was significantly lower than IL-6 $(0.83 \mathrm{mg} / \mathrm{dl}), \mathrm{MSCs}(0.63 \mathrm{mg} / \mathrm{dl})$ and $\mathrm{CCl}_{4}(1.17 \mathrm{mg} / \mathrm{dl})$ treatment groups (Figure 6B). Collectively, these results indicate that combined treatment with MSCs and IL-6 results in higher recovery of hepatic function than either of the treatment alone compared to $\mathrm{CCl}_{4}$ treated mice.

\section{Discussion}

Liver fibrosis is a progressive disease that involves disruption of hepatic tissue architecture and accumulation of extracellular matrix in response to pathological insults. Hepatocyte apoptosis as a consequence of prolonged liver disease is one of the hallmarks of liver fibrosis and leads to development of a fibrotic scar [24]. Bone marrow derived mesenchymal stem cells (MSCs) have been
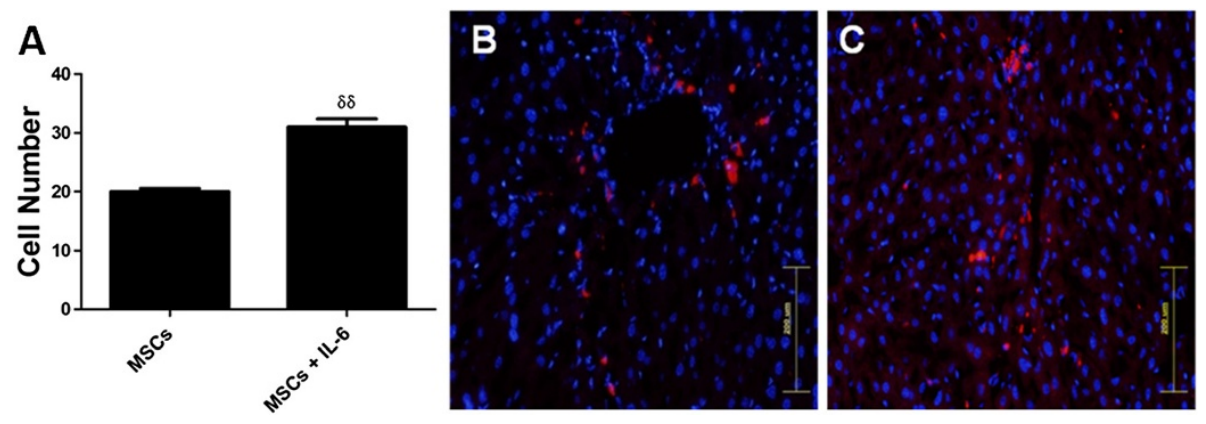

Figure 3 MSC homing in injured liver 30 days post transplantation. A) Quantification of transplanted MSCs $(n=6)$. B) Injured liver with MSCs Transplantation. C) Injured liver with combined treatment (MSCs + IL-6). MSCs vs MSCs + IL-6 ${ }^{*} p<0.05,{ }^{* *} p<0.01$ and ${ }^{* * *} p<0.001$. 

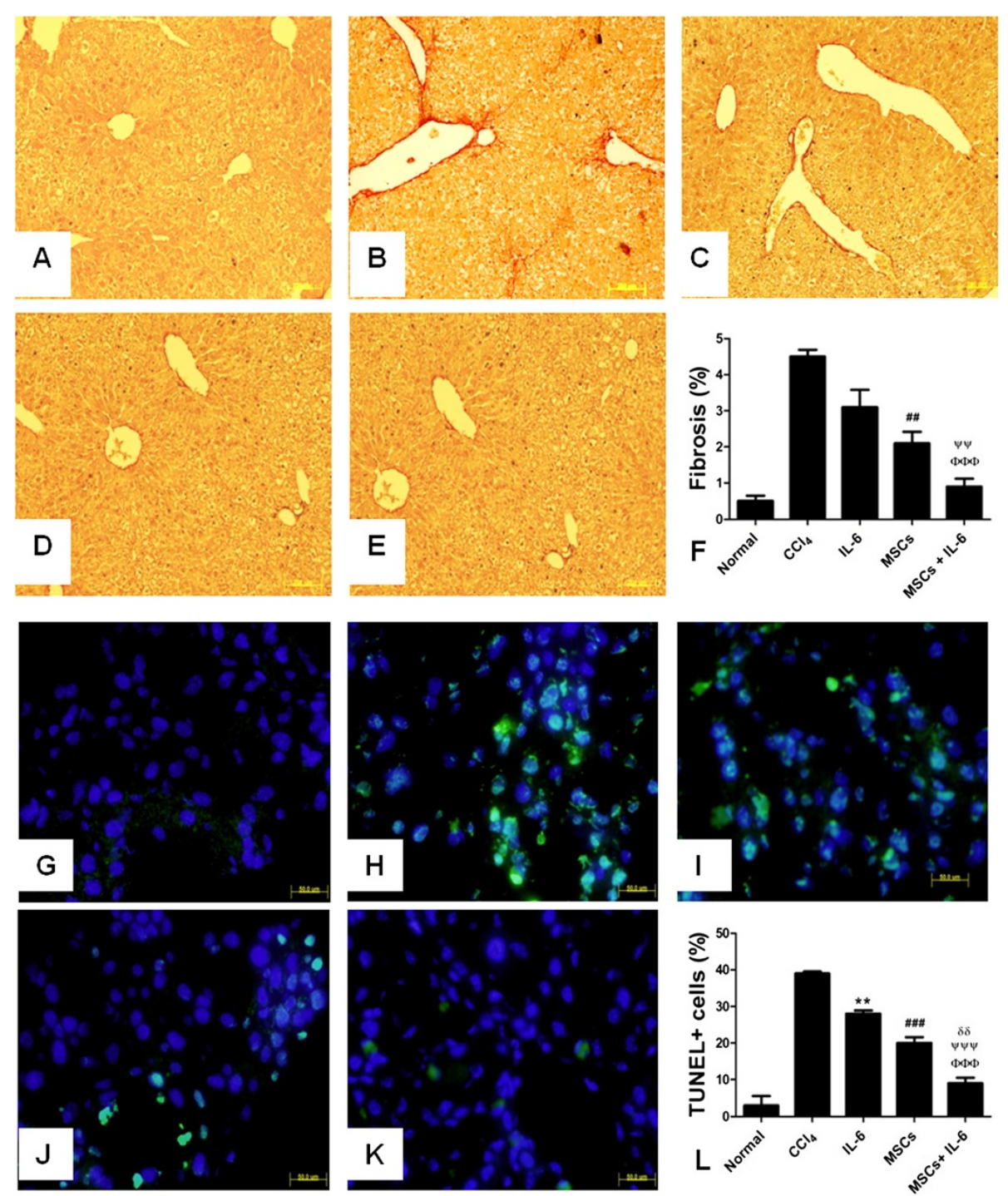

Figure 4 Reduced fibrosis and apoptosis in injured liver treated with MSCs + IL-6. A: Normal, B: CCl 4 injury, C: IL-6 treated, D: MSCS transplanted, E: IL-6 + MSCs transplanted, F: Graphical presentation of collagen levels ( $\mathrm{n}=)$. CCl 4 Vs IL-6 NS, CCl 4 vs MSCs ${ }^{*} p<0.05$, \#\# $p<0.01$ and

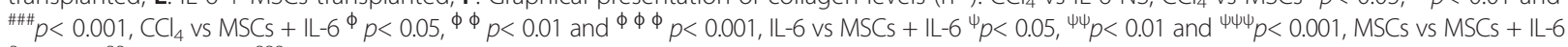
$\delta_{p<0.05,}{ }^{\delta} \delta_{p<0.01}$ and ${ }^{\delta \delta \delta} p<0.001$. G-L Estimation of apoptosis in control fibrotic liver and treatment groups through TUNEL Assay. G: Normal, H: CCl 4 injury, I: IL-6 treated, J: MSCs transplanted, K: IL-6 + MSCs transplanted, L: Graphical presentation of apoptotic positive cells in different treatment groups

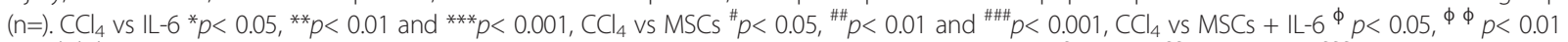

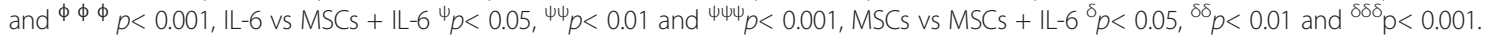

shown to develop into functional hepatocytes in vitro [25] and in vivo [26] proclaiming them as possible source for repair of damaged liver. However, recent reports indicate poor survival and engraftment of MSCs in hostile hepatic milieu [15,27]. There is a dire need of strategies that protect hepatocytes against injury promoting liver microenvironment for MSCs engraftment and survival. Therefore, in the present study we combined MSC transplantation for repair of fibrotic liver with IL-6 treatment with the premise that IL-6 treatment will protect hepatocytes from fibrotic injury thereby priming MSCs engraftment and survival.

A large number of studies have been conducted aimed at protecting hepatocytes from pathological injury thereby augmenting hepatic milieu and promoting repair. Hepatocyte protection from hypoxic injury was recently demonstrated by treatment with methylene blue and epimorphin in rats $[28,29]$. Similarly, treatment with different cytoprotective chemicals can protect hepatocytes against toxic injury [30-32]. Alternatively, treatment 


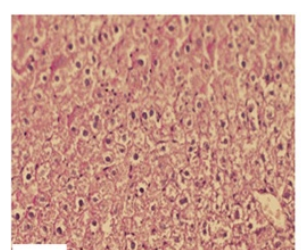

A
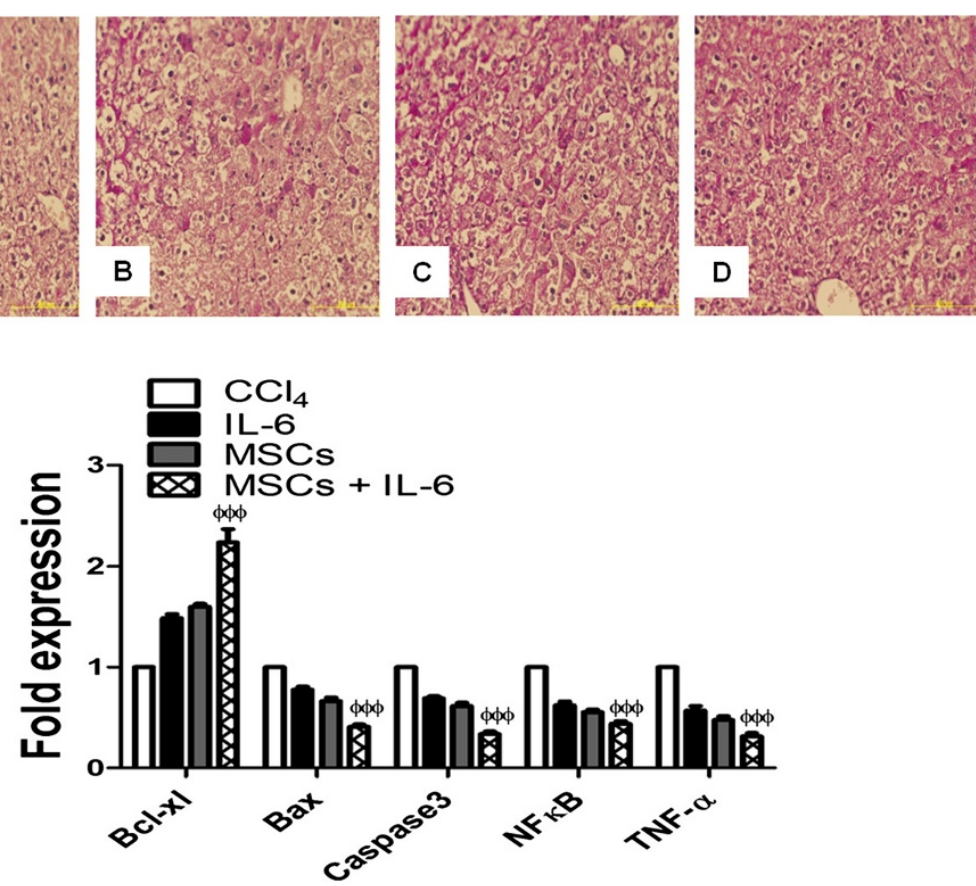

Figure 5 Increased glycogen storage and survival signaling in livers after treatment with MSCs + IL-6. PAS staining of liver section from A) - $\mathrm{CCl}_{4}$, B) IL-6, C) MSCS, D) MSCS + IL-6 treated animals ( $\left.\mathrm{n}=\right)$. E) Gene expression analysis of bcl-xl, bax, caspase-3, NFKB, TNF-a as measured by quantitative RT-PCR $(n=)$. CCl 4 vS MSCS + IL-6 * $p<0.05$, $^{* *} p<0.01$ and ${ }^{* *} p<0.001$.

with cytokines released by hepatocytes in response to injury can enhance hepatocyte survival by activation of pro survival cascades. Preconditioning hepatocytes with IL-6, a major regulator of hepatic regeneration, before induction of injury promotes proliferation [13,33,34] and has a protective effect against apoptosis [11], ethanol and TNF induced injuries [35]. Conversely, IL-6 -/mice display delayed weight recovery, defective DNA synthesis post operative mortality and severe liver fibrosis [36-38]. Exogenous administration of IL-6 in
IL-6 -/- mice enhanced DNA replication to the levels seen in wild type mice $[13,34]$. Therefore, we sought to augment fibrotic liver tissue with exogenous IL-6 treatment with the premise that IL-6 administration will protect existing hepatocytes from $\mathrm{CCl}_{4}$ induced injury. Increased hepatocyte survival will prime the hepatic milieu for MSCs engraftment and survival leading to increase hepatic repair.

Recent evidence shows that soluble factors produced by bone marrow cells can functionally enhance hepatocytes in a co-culture system [21,39]. Conversely, IL-6
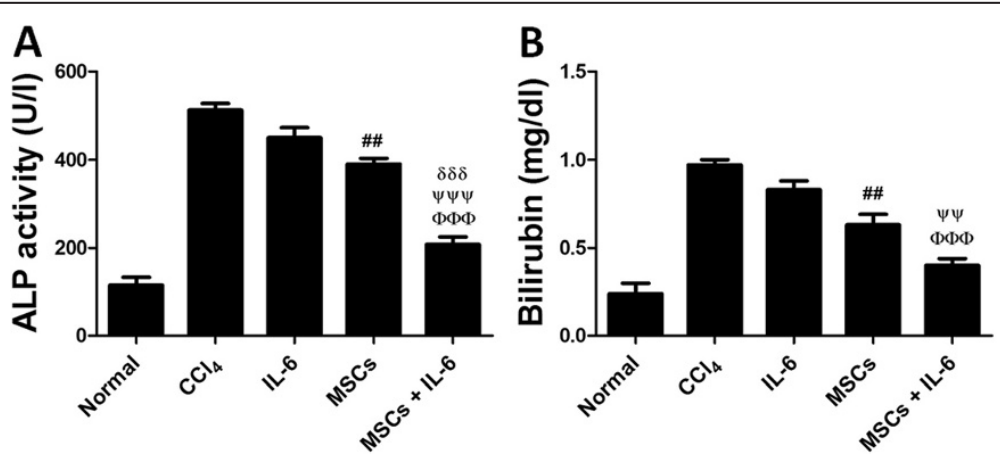

Figure 6 Liver function tests. A) Alkaline phosphatase in serum of all animal groups B) Bilirubin serum levels in all animal groups ( $n=10 / \mathrm{group}$ ). $\mathrm{CCl} \mathrm{V}_{4} \mathrm{Vs}$

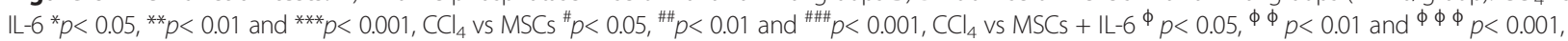

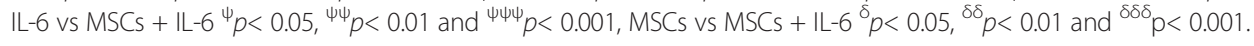


pretreated hepatocytes were co-cultured with MSCs to determine whether combined treatment with IL-6 and MSCs can protect hepatocytes against $\mathrm{CCl}_{4}$ injury. Increased survival was observed in hepatocytes pretreated with IL-6 co-cultured with MSCs in response to $\mathrm{CCl}_{4}$ induced injury as evidenced by decreased expression of pro apoptotic markers (BAX, Caspase-3, TNF- $\alpha N F \kappa B)$ and LDH activity (Figure 2). Interestingly, co-culture of MSCs alone or IL-6 treatment did not result in a significant increase in hepatocyte survival compared to the combination of MSC co-culture with IL-6 treatment. Therefore, combination of IL- 6 and soluble factors released by MSCs can result in significantly improved hepatocyte survival against $\mathrm{CCl}_{4}$ induced fibrosis than any other treatment modality.

Beneficial effect of combined MSC and IL- 6 treatment on hepatocyte survival in vitro was extended in vivo to demonstrate that IL-6 can enhance hepatocyte survival and improve hepatic milieu that would lead to increased efficacy of MSC therapy for the repair of fibrotic liver. Recent studies show that IL-6-/- mice demonstrate hepatocyte apoptosis after treatment with ethanol emphasizing the role of IL- 6 in liver protection against drug induced hepatoxicity [35]. Moreover, IL-6 can exert an antioxidant effect on hepatocytes by imparting protection against ROS while $B c l 2$ and $B c l-x l$ levels were shown to increase in IL-6 dependent manner [11]. Improvement in hepatic environment by virtue of increased hepatocyte protection by IL- 6 administration against $\mathrm{CCl}_{4}$ induced injury would enable enhanced MSC survival and hepatic repair. Concurrently, increased MSC homing was observed in IL-6 treated fibrotic livers compared to non-treated hepatic tissue (Figure 3) and was associated with reduced fibrosis and apoptosis (Figure 4). In addition, combined treatment of MSCs and IL-6 resulted in increased glycogen storing ability of livers affected by $\mathrm{CCl}_{4}$ induced fibrosis in conjunction with increased expression of $B c l-x l$ and decreased expression of Bax, caspase-3, TNF- $\alpha$ and $N F \kappa B$ (Figure 5). Augmented hepatic environment evidenced by increased hepatocyte survival leads to increased MSCs survival that significantly improved hepatic function demonstrated by serum levels of ALP and Bilirubin (Figure 6).

Cell therapy remains an attractive therapeutic modality for the treatment of liver fibrosis however, the efficacy of bone marrow derived MSCs within the hostile liver tissue remains a serious concern. MSCs have the ability to promote hepatocyte survival via paracrine mediated effects $[21,39]$ and can differentiate into functional hepatocytes. Therefore, augmenting MSC capability for liver repair by enhancing liver tissue environment by IL-6 administration can lead to increased MSC homing and engraftment. Increased MSC survival within fibrotic liver pretreated with IL-6 leads to functional hepatic improvement and may be a novel therapeutic strategy for the treatment of liver fibrosis.

\section{Conclusion}

We have demonstrated that IL-6 administration can significantly enhance the ability of MSCs to repair liver after $\mathrm{CCl}_{4}$ induced fibrosis. IL-6 is one of the pleiotropic inflammatory cytokines produced by the liver in response to injury. Recent evidence shows that IL- 6 can enhance hepatocyte survival while IL-6 depleted mice have enhanced liver fibrosis. Furthermore, studies demonstrating MSC therapy for repair of liver fibrosis has debatable results warranting a new strategy to enhance the potential of MSCs for repair of damaged liver. MSC transplantation in fibrotic livers treated together with IL-6 results increases MSC engraftment leading to improved hepatic function. Therefore, we report here a clinically viable therapeutic option combining IL-6 treatment with MSCs transplantation for the treatment of fibrotic liver.

\section{Competing interests}

The authors have no financial conflicts of interest.

\section{Authors' contributions}

GAN and SM designed research; GAN, GA, SS performed research; GAN and SM analyzed data; and GAN, SM, MK, SNK and SR. wrote the paper.

All authors have read and approved the manuscript.

\section{Acknowledgments}

We thank our colleagues for the review of this manuscript. This work was supported by research grants from the Higher Education Commission (HEC) of Pakistan.

Received: 29 December 2012 Accepted: 1 March 2013

Published: 26 March 2013

\section{References}

1. Zheng JF, Liang LJ: Intra-portal transplantation of bone marrow stromal cells ameliorates liver fibrosis in mice. Hepatobiliary Pancreat Dis Int 2008, 7(3):264-270.

2. Aurich $\mathrm{H}$, Sgodda M, Kaltwasser $\mathrm{P}$, Vetter M, Weise A, Liehr T, Brulport M, Hengstler JG, Dollinger MM, Fleig WE, Christ B: Hepatocyte differentiation of mesenchymal stem cells from human adipose tissue in vitro promotes hepatic integration in vivo. Gut 2009, 58(4):570-581.

3. Caplan Al, Dennis JE: Mesenchymal stem cells as trophic mediators. J Cell Biochem 2006, 98:1076-1084.

4. Parekkadan B, van Poll D, Suganuma K, Carter EA, Berthiaume F, Tilles AW, Yarmush ML: Mesenchymal stem cell-derived molecules reverse fulminant hepatic failure. PLoS One 2007, 2:e941.

5. Sakaida I, Terai S, Yamamoto N, Aoyama K, Ishikawa T, Nishina H, Okita K: Transplantation of bone marrow cells reduces $\mathrm{CCl} 4$-induced liver fibrosis in mice. Hepatology 2004, 40:1304-1311.

6. Cho KA, Lim GW, Joo SY, Woo SY, Seoh JY, Cho SJ, Han HS, Ryu KH: Transplantation of bone marrow cells reduces $\mathrm{CCl} 4$-induced liver fibrosis in mice. Liver Int 2011, 31(7):932-939.

7. Fang B, Shi M, Liao L, Yang S, Liu Y, Zhao RC: Systemic infusion of FLK1+ mesenchymal stem cells ameliorates carbon tetrachloride-induced liver fibrosis in mice. Transplant 2004, 78:83-88.

8. Higashiyama R, Inagaki $Y$, Hong $Y Y$, Kushida M, Nakao S, Niioka M, Watanabe T, Okano H, Matsuzaki Y, Shiota G, Okazaki I: Bone marrowderived cells express matrix metalloproteinases and contribute to regression of liver fibrosis in mice. Hepatol 2007, 45(1):213-222.

9. Kishimoto T: IL-6: From its discovery to clinical applications. Int Immunol 2010, 22(5):347-352. 
10. Czaja M, Xu J, Alt E: Prevention of carbon tetrachloride-induced rat liver injury by soluble tumor necrosis factor receptor. Gastroenterol 1995, 108:1849-1854.

11. Kovalovich K, Li W, DeAngelis R, Greenbaum L, Cilberto G, Taub R: Interleukin- 6 protects against Fas-mediated death by establishing a critical level of anti-apoptotic hepatic proteins FLIP, Bcl-2, and Bcl-XL. J Biol Chem 2001, 276:26605-26613.

12. Aldeguer X, Debonera F, Shaked A, Krasinkas AM, Gelman AE, Que X, Alison MR, Poulsom R, Jeffery R, Dhillon AP, Quaglia A, Jacob J, Novelli M, Prentice G, Williamson J, Wright NA: Hepatocytes from non-hepatic adult stem cells. Nature 2001, 6:257-264.

13. Sudo K, Yamada Y, Saito K, Shimizu S, Ohashi H, Kato T, Moriwaki $H$, Ito $H$, Seishima M: TNF- $a$ and IL- 6 signals from the bone marrow derived cells are necessary for normal murine liver regeneration. Biochim Biophys Acto 2008, 1782:671-679.

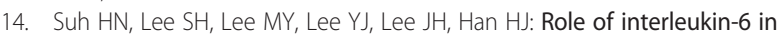
the control of DNA synthesis of hepatocytes: involvement of PKC, p44/42 MAPKs, and PPAR delta. Cell Physiol Biochem 2008, 22(5-6):673-684.

15. Popp FC, Slowik P, Eggenhofer E, Renner P, Lang SA, Stoeltzing O, Geissler EK, Piso P, Schlitt HJ, Dahlke MH: No contribution of multipotent mesenchymal stromal cells to liver regeneration in a rat model of prolonged hepatic injury. Stem Cells 2007, 25(3):639-645

16. di Bonzo LV, Ferrero I, Cravanzola C, Mareschi K, Rustichell D, Novo E, Sanavio F, Cannito S, Zamara E, Bertero M, Davit A, Francica S, Novelli F, Colombatto S, Fagioli F, Parola M: Human mesenchymal stem cells as a two-edged sword in hepatic regenerative medicine: engraftment and hepatocyte differentiation versus profibrogenic potential. Gut 2008, 57(2):223-231.

17. Khan M, Mohsin S, Khan SN, Riazuddin S: Repair of senescent myocardium by mesenchymal stem cells is dependent on the age of donor mice. J Cell Mol Med 2011, 15(7):1515-1527.

18. Okubo H, Matsushita M, Kamachi H, Kawai T, Takahashi M, Fujimoto T, Nishikawa K, Todo S: A novel method for faster formation of rat liver cell spheroids. Artif Organs 2002, 26(6):497-505.

19. Zhang S, Chen L, Liu T, Zhang B, Xiang D, Wang Z, Wang Y: Human umbilical cord matrix stem cells efficiently rescue acute liver failure through paracrine effects rather than hepatic differentiation. Tissue Eng Part A 2012, 18(13-14):1352-1364.

20. Dvorak Z, Kosina P, Walterova D, Simanek V, Bachled P, Ulrichova J: Primary cultures of human hepatocytes as a tool in cytotoxicity studies: cell protection against model toxins by flaonolignans obtained from Silybum marianum. Toxicol Lett 2003, 137:201-212.

21. Ijima $H$, Matsuo $T$, Kawakami $K$ : The mixed co-culture effect of primary rat hepatocytes and bone marrow cells is caused by soluble factors derived from bone marrow cells. J Biosci Bioeng 2008, 105(3):226-231.

22. Cai Y, Gong LK, Qi XM, Li XH, Ren J: Apoptosis initiated by carbon tetrachloride in mitochondria of rat primary cultured hepatocytes. Acta Pharmacol Sin 2005, 26(8):969-975.

23. Mohsin S, Shams S, Ali Nasir G, Khan M, Javaid Awan S, Khan SN, Riazuddin S: Enhanced hepatic differentiation of mesenchymal stem cells after pretreatment with injured liver tissue. Differ 2011, 81(1):42-48.

24. Friedman SL: Hepatic fibrosis-Overview. Toxicol 2008, 254:120-129.

25. Kuo TK, Hung SP, Chuang CH, Chen CT, Shih YR, Fang SC, Yang WW, Lee OK: Stem cell therapy for liver disease: parameters governing the success of using bone marrow mesenchymal stem cells. Gastroenterol 2008, 134(7):2111-21, 2121.e1-3.

26. Zhao DC, Lei JX, Chen R, Yu WH, Zhang XM, Li SN, Xiang P: Bone marrowderived mesenchymal stem cells protect against experimental liver fibrosis in rat. World J Gastroentrol 2005, 14:3431-3440.

27. Song $H$, Kwon $K$, Lim S, Kang SM, Ko YG, Xu Z, Chung JH, Kim BS, Lee $H$, Joung B, Park S, Choi D, Jang Y, Chung NS, Yoo KJ, Hwang KC: Transfection of mesenchymal stem cells with the FGF-2 gene improves their survival under hypoxic conditions. Mol Cells 2005, 19(3):402-407.

28. Muratsubaki H, Yajima N, Yoneda H, Enomoto K, Tezuka T: Methylene blue protection against hypoxic injury in primary cultures of rat hepatocyte monolayers. Cell Biochem Func 2008, 26(2):275-278.

29. Kinoshita N, Horie Y, Ohshima S, Hirai Y, Dohmen T, Jin M, Matsuhashi T, Sasaki J, Sasaki T, lizuka M, Ohnishi H: Epimorphin protects hepatocytes from oxidative stress by inhibiting mitochondrial injury. $J$ Gastroenterol Hepatol 2011, 26(1):201-206.

30. Klouz A, Saïd DB, Ferchichi H, Kourda N, Ouanes L, Lakhal M, Tillement JP, Morin D: Protection of cellular and mitochondrial functions against liver ischemia by $\mathrm{N}$-benzyl-N'-(2-hydroxy-3,4-dimethoxybenzyl)-piperazine (BHDP), a sigma1 ligand. Eur J Pharmacol 2008, 578(2-3):292-299.
31. Lotková H, Cervinková Z, Kucera O, Rousar T, Kriváková P: S-adenosylmethionine exerts a protective effect against thioacetamide-induced injury in primary cultures of rat hepatocytes. Altern Lab Anim 2007, 35(3):363-371.

32. Rubiolo JA, Mithieux G, Vega FV: Resveratrol protects primary rat hepatocytes against oxidative stress damage: activation of the Nrf2 transcription factor and augmented activities of antioxidant enzymes. Eur J Pharmacol 2008, 591(1-3):66-72.

33. Zimmers TA, McKillop $I H$, Pierce $R H$, Yoo JY, Koniaris LG: Massive liver growth in mice induced by systemic interleukin 6 administration. Hepatol 2003, 38:326-334.

34. Jin X, Zimmers TA, Perez EA, Pierce RH, Zhang Z, Koniaris LG: Paradoxical effects of short- and long-term interleukin- 6 exposure on liver injury and repair. Hepatol 2006, 43(3):474-484

35. Hong F, Kim W, Tian Z, Jaruga B, Ishac E, Shen X, Gao B: Elevated interleukin-6 during ethanol consumption acts as a potential endogenous protective cytokine against ethanol-induced apoptosis in the liver: involvement of induction of $\mathrm{BCl}-2$ and $\mathrm{BCl}-\mathrm{xL}$ proteins. Oncog 2002, 21:32-43.

36. Icressman DE, Greenbaum LE, DeAngelis RA, Ciliberto G, Furth EE, Poli V, Taub R: Liver failure and defective hepatocyte regeneration in interleukin-6-deficient mice. Sci 1996, 274:1379-1383.

37. Ezure T, Sakamoto T, Tsuji H, Lunz JG, Murase N, Fung JJ, Demetris AJ: The development and compensation of biliary cirrhosis in interleukin-6-deficient mice. Am J Pathol 2000, 156:1627-1639.

38. Kovalovich K, DeAngelis RA, Li W, Furth EE, Ciliberto G, Taub R: Increased toxin-induced liver injury and fibrosis in interleukin-6-deficient mice. Hepatol 2000, 31:149-159.

39. Mizuguchi T, Hui T, Palm K, Sugiyama N, Mitaka T, Demetriou AA, Rozga J: Enhanced proliferation and differentiation of rat hepatocytes cultured with bone marrow stromal cells. J Cell Physio/ 2001, 189(1):106-119.

\section{doi:10.1186/1479-5876-11-78}

Cite this article as: Nasir et al:: Mesenchymal stem cells and Interleukin6 attenuate liver fibrosis in mice. Journal of Translational Medicine 2013 $11: 78$.

\section{Submit your next manuscript to BioMed Central and take full advantage of:}

- Convenient online submission

- Thorough peer review

- No space constraints or color figure charges

- Immediate publication on acceptance

- Inclusion in PubMed, CAS, Scopus and Google Scholar

- Research which is freely available for redistribution 